\title{
Impact of electrocardiographic morphology on clinical outcomes in patients with non-ST elevation myocardial infarction receiving coronary angiography and intervention: A retrospective study
}

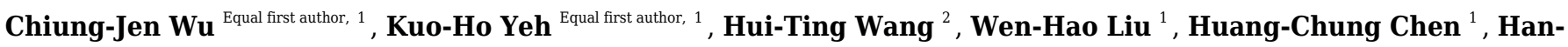 \\ Tan Chai ${ }^{1}$, Wen-Jung Chung ${ }^{1}$, Shukai Hsueh ${ }^{1}$, Chien-Jen Chen ${ }^{1}$, Hsiu-Yu Fang ${ }^{1}$, Yung-Lung Chen ${ }^{\text {Corresp. } 1}$ \\ 1 Division of Cardiology, Department of Internal Medicine, Kaohsiung Chang Gung Memorial Hospital, Kaohsiung, Taiwan \\ 2 Emergency Department, Kaohsiung Chang Gung Memorial Hospital, Kaohsiung, Taiwan \\ Corresponding Author: Yung-Lung Chen \\ Email address: lung@cgmh.org.tw
}

Background. The impact of electrocardiography (ECG) morphology on clinical outcomes in patients with non-ST segment elevation myocardial infarction (NSTEMI) receiving percutaneous coronary intervention $(\mathrm{PCl})$ is unknown. This study investigated whether different ST morphologies had different clinical outcomes in patients with NSTEMI receiving $\mathrm{PCl}$.

Methods. This retrospective study analyzed record-linked data of 362 patients who had received PCl for NSTEMI between January 2008 and December 2010. ECG revealed ST depression in 67 patients, inverted T wave in 91 patients, and no significant ST-T changes in 204 patients. The primary endpoint was longterm all-cause mortality. The secondary endpoint was long-term cardiac death and non-fatal major adverse cardiac events.

Results. Compared to those patients whose ECG showed an inverted T wave and non-specific ST-T changes, patients whose ECG showed ST depression had more diabetes mellitus, advanced chronic kidney disease (CKD) and left main artery disease, as well as more in-hospital mortality, cardiac death and pulmonary edema during hospitalization. Patients with ST depression had a significantly higher rate of long-term total mortality and cardiac death. Finally, multiple stepwise Cox regression analysis showed that an advanced Killip score, age, advanced CKD, prior percutaneous transluminal coronary angioplasty and ST depression were independent predictors of the primary endpoint.

Conclusions. Among NSTEMI patients undergoing coronary angiography, those with ST depression had more in-hospital mortality and cardiac death. Long-term follow-up of patients with ST depression consistently reveals poor outcomes. 
1 Impact of electrocardiographic morphology on clinical outcomes in patients with non-ST

2 elevation myocardial infarction receiving coronary angiography and intervention: A

3 retrospective study

4

5 Chiung-Jen $\mathrm{Wu}, \mathrm{MD}^{1}$, Kuo-Ho Yeh, MD ${ }^{1 *}$, Hui-Ting Wang, MD², Wen-Hao Liu, MD ${ }^{1}$, Huang-

6 Chung Chen, MD ${ }^{1}$, Han-Tan Chai, MD ${ }^{1}$, Wen-Jung Chung, MD ${ }^{1}$, Shukai Hsueh, MD ${ }^{1}$, Chien-

7 Jen Chen, MD ${ }^{1}$, Hsiu-Yu Fang, MD ${ }^{1}$, Yung-Lung Chen, MD $^{1}$

8

$9{ }^{1}$ Division of Cardiology, Department of Internal Medicine, Kaohsiung Chang Gung Memorial

10 Hospital, Kaohsiung, Taiwan

$11{ }^{2}$ Emergency Department, Kaohsiung Chang Gung Memorial Hospital, Kaohsiung, Taiwan

$12{ }^{*}$ Contributions equal to the first author

13

14 Corresponding Author: Correspondence and reprint requests should be made to: Yung-Lung Chen, MD, Division of Cardiology, Department of Internal Medicine, Kaohsiung Chang Gung Memorial Hospital 123 Ta Pei Road, Niao Sung District, Kaohsiung City, 83301, Taiwan,

17 Republic of China

Email address: lung@cgmh.org.tw

19

20

21

22

23

24

25

26

27

28

29

30

31

32

33

34

35

36

37

38

39

40 


\section{Abstract}

42 Background:

43 The impact of electrocardiography (ECG) morphology on clinical outcomes in patients with non-

44 ST segment elevation myocardial infarction (NSTEMI) receiving percutaneous coronary

45 intervention (PCI) is unknown. This study investigated whether different ST morphologies had

46 different clinical outcomes in patients with NSTEMI receiving PCI.

47 Methods:

48 This retrospective study analyzed record-linked data of 362 patients who had received PCI for 49 NSTEMI between January 2008 and December 2010. ECG revealed ST depression in 67

50 patients, inverted $\mathrm{T}$ wave in 91 patients, and no significant ST-T changes in 204 patients. The

51 primary endpoint was long-term all-cause mortality. The secondary endpoint was long-term

52 cardiac death and non-fatal major adverse cardiac events.

53 Results:

54 Compared to those patients whose ECG showed an inverted T wave and non-specific ST-T 55 changes, patients whose ECG showed ST depression had more diabetes mellitus, advanced 56 chronic kidney disease (CKD) and left main artery disease, as well as more in-hospital mortality, 57 cardiac death and pulmonary edema during hospitalization. Patients with ST depression had a 58 significantly higher rate of long-term total mortality and cardiac death. Finally, multiple stepwise 59 Cox regression analysis showed that an advanced Killip score, age, advanced CKD, prior 60 percutaneous transluminal coronary angioplasty and ST depression were independent predictors

61 of the primary endpoint.

62 Conclusions:

63 Among NSTEMI patients undergoing coronary angiography, those with ST depression had more 64 in-hospital mortality and cardiac death. Long-term follow-up of patients with ST depression 65 consistently reveals poor outcomes. 


\section{Introduction}

74 According to clinical guidelines, the definition of non-ST segment elevation myocardial

75 infarction (NSTEMI) is clinical chest tightness and elevation of cardiac enzyme without ST

76 elevation on electrocardiography (ECG) [1]. Early percutaneous coronary intervention (PCI) is

77 one of the standard treatments for high-risk NSTEMI patients, including those patients with

78 refractory angina, unstable hemodynamic status, heart failure symptoms, malignant tachyarrhythmia, or a

79 higher risk score [1-4]. The ECG pattern is one of the components of some risk scores used for 80 risk stratification, especially in the mainly pre-thrombolytic and thrombolytic era [1]. However,

81 the influence of different ECG patterns on the clinical outcome of NSTEMI is unclear, especially

82 in the PCI era, and the impact of the ECG pattern on risk stratification may be different in the

83 thrombolytic and PCI era. Furthermore, no studies have focused on the impact of ECG patterns

84 on long-term outcomes in this specific population after PCI. This study was aimed at evaluating

85 the prognostic impact of clinical ECG patterns on clinical outcomes of NSTEMI patients

86 undergoing PCI.

\section{Materials \& Methods}

88 Setting and patient population

89 This study retrospectively analyzed all patients who had received PCI after being diagnosed with

90 NSTEMI at Kaohsiung Chang Gung Memorial Hospital from January 2008 to December 2010.

91 Data were collected as previously described in Wang et al. [5]. Specifically, the definition of

92 NSTEMI was typical chest pain, troponin-I elevation $\geq 0.5 \mathrm{ng} / \mathrm{ml}$ and no ST-segment elevation

93 by clinical ECG finding. The inclusion criterion in our study was patients with NSTEMI who

94 received angiography within 72 hours after presentation. The exclusion criteria included the

95 availability of only one set of troponin-I data, the absence of a rising pattern of the troponin-I

96 level during follow-up, or delayed PCI (more than 72 hours) due to other etiologies (mostly to

97 poor renal function, active bleeding and sepsis). Stent implantations for stenotic vessels were

98 performed according to clinical guidelines [6]. Data collection included baseline characteristics,

99 ECG findings, left ventricular ejection fraction (LVEF) obtained by echocardiography or left

100 ventricular angiography, coronary angiography and PCI data. Blood samples were evaluated

101 when patients arrived at the ER (emergency room), and ECG was performed after the patients

102 arrived, or if they had acute typical chest pain during hospitalization. We analyzed the in-hospital

103 outcomes, including total mortality, cardiac death, ventricular arrhythmia and pulmonary edema. 
104 Patients received continued clinical follow-up after being discharged. The primary endpoint of 105 this study was long-term mortality. The secondary endpoint was long-term cardiac death and 106 non-fatal major adverse cardiac events (MACE), which were defined as target vessel 107 revascularization, myocardial infarction (MI), stroke, and hospitalization for heart failure. An 108 advanced Killip score was defined as a score $\geq 3$ and advanced chronic kidney disease (CKD) 109 was defined as an estimated glomerular filtrating rate $<60 \mathrm{ml} / \mathrm{min} / 1.73 \mathrm{~m} 2$. The study protocol 110 was approved by the Institutional Review Committee for Human Research of Kaohsiung Chang 111 Gung Memorial Hospital (201900344B0). The need for consent was waived by the Institutional

112 Review Board of Kaohsiung Chang Gung Memorial Hospital.

\section{Electrocardiography (ECG) definition}

114 The ECG findings were classified as no significant ST-T change, ST depression or T wave

115 inversion. ST depression was defined as horizontal or down-sloping ST segment depression $\geq 1$

$116 \mathrm{mV}$ at $80 \mathrm{~ms}$ after a $\mathrm{J}$ point over at least 2 consecutive leads. $\mathrm{T}$ wave inversion was defined as

117 the amplitude of an inverted $\mathrm{T}$ wave of at least $1 \mathrm{~mm}$ over at least 2 consecutive leads. Patients

118 with $1 \mathrm{~mm}$ ST-segment depression and T-wave inversion were classified as having ST

119 depression. ECG results that did not meet these criteria without significant ST segment elevation 120 were defined as showing no significant ST-T change. Those patients who had some ST elevation, but 121 not enough to meet STEMI criteria, were also classified as "no significant ST-T change".

\section{Coronary angiography and stenting}

123 Coronary stent implantation was performed using procedures and protocols described in our 124 previous publications $[5,7,8]$. Briefly, diagnostic catheterization and intervention were performed as soon as possible within 72 hours after the diagnosis of NSTEMI was confirmed. Before the procedure, dual antiplatelets (aspirin and clopidogrel) were given, and unfractionated heparin or low molecular weight heparin was given for heparinization, based on renal function. We did total revascularization for culprit lesions and all other radiographically significant stenoses at the index procedure for those patients presenting with NSTEMI, or treated non-culprit lesions at the staged procedure during the index admission. Left main (LM) lesions with $\geq 50 \%$ stenosis and lesions of the main trunk of triple vessels with more than $70 \%$ stenosis were usually treated (stenting if the vascular reference was $\geq 2.5 \mathrm{~mm}$ or balloon angioplasty for vascular references of 2.0-2.5 mm). Chronic total occlusive lesions usually did not undergo revascularization during the index procedure. We usually evaluated myocardial perfusion using a thallium-201 scan thereafter, during the OPD follow-up, and 
136 of balloons prior to stent implantation. Most patients underwent post-stenting dilatation with a high-

137 pressure balloon. Multiple-vessel disease (MVD) was defined as stenosis $\geq 50 \%$ in $\geq 2$ major 138 epicardial coronary arteries.

139 Post-percutaneous coronary intervention management

140 Patients were treated according to current clinical guidelines for post-PCI management [5]. Our patients

141 were covered under Taiwan's National Health Insurance (NHI) program, which is a compulsory single-

142 payer healthcare system featuring care coverage for more than $99.8 \%$ of the population in Taiwan. In

143 accordance with NHI reimbursement criteria, dual antiplatelet therapies were given for at least 9 months

144 and statin therapy was given for those patients with low-density lipoprotein $\geq 100 \mathrm{mg} / \mathrm{dl}$, in the absence of

145 contraindications. Patients were referred for cardiac rehabilitation routinely and the compliance rate was

146 about 90\%. Major risk factors such as smoking, hypertension, dyslipidemia, physical inactivity, obesity,

147 and diabetes mellitus (DM) were also treated.

\section{Statistical analysis}

149 Unless otherwise stated, data were expressed as means \pm standard deviation or as a number

150 (percentage). Differences in continuous variables were analyzed using one-way analysis of

151 variance for continuous variables, and categorical variables were analyzed using the chi-square

152 test. Pairwise post hoc multiple comparisons between any 2 study groups were made using the

153 Bonferroni adjustment. For long-term outcome analysis, those patients with $\mathrm{T}$ wave inversion

154 and no significant ST change pattern were defined as the no-ST depression group. The

155 independent predictors of long-term mortality were analyzed using the multiple stepwise Cox

156 regression method. Event-free survival in patients with and without ST depression and also with

157 different ECG patterns was evaluated and compared by the Kaplan-Meier method and log rank

158 test. Statistical analysis was performed with statistical software (SPSS Statistics for Windows,

159 version 17.0; SPSS Inc., Chicago, IL, U.S.A.). A 2-tailed $p$ value $<0.05$ was considered

160 statistically significant.

161 Results

162 Baseline characteristics and in-hospital outcomes of the study patients

163 During the study period, 409 patients who had a clinical diagnosis of NSTEMI received coronary 164 angiography and PCI. Forty-seven patients who met our exclusion criteria were excluded from 165 analysis. Of the 362 patients enrolled in this study, 264 (72.9\%) were males and the average age 166 was $65.6 \pm 12.2$ years. Sixty-seven (18.5\%) patients were classified as having ST depression, 91 
167 (25.1\%) as having T wave inversion, and the remaining 204 (56.4\%) as having no significant ST168 T change pattern. Patients with ST depression had a significantly higher percentage of DM and 169 CKD than patients with T wave inversion and no significant ST-T changes (both $P<.05$ ). More 170 of the patients with ST depression and T wave inversion had a past history of old MI and 171 coronary artery bypass surgery $(\mathrm{CABG})$ than the patients with no significant ST-T changes (both $172 P<0.05)$. More patients with ST depression had an advanced Killip score, and patients with T 173 wave inversion had a lower body mass index than patients with no significant ST-T change (both $174 P<0.05)$. There was no significant difference in age, male gender, current smoker, 175 hypertension, dyslipidemia, old stroke, peripheral vascular disease, percutaneous transluminal 176 coronary angioplasty, or time to angiography among patients with different ECG patterns.

177 Patients with ST depression had a higher creatinine level than other patients and a higher 178 troponin-I level than patients with T wave inversion (both $P<0.05$ ). There was no significant 179 difference in LVEF among patients with different ECG patterns (Table 1).

180 Total revascularization for culprit lesions and all other radiographically significant stenoses 181 were achieved in $95.6 \%$ of patients during hospitalization $(93.8 \%$ at the index procedure 182 simultaneously for those patients presenting with NSTEMI and 1.8\% at the staged procedure for 183 non-culprit lesions during the index admission.) In terms of coronary angiography and PCI 184 findings, more patients presenting with ST depression had left main disease than patients 185 presenting with other ECG findings $(P<0.05)$. There was no difference in the percentage of 186 significant coronary artery disease (CAD), MVD, total stents number and types and post-PCI 187 final thrombolysis in MI (TIMI)-3 flow among patients with different ECG patterns. Patients 188 presenting with an ST depression pattern had more total in-hospital mortality, cardiac death and 189 pulmonary edema events $(P<0.05)$. The number of events of in-hospital ventricular tachycardia 190 and fibrillation did not differ.

191 Primary outcome analysis: long-term mortality

192 The mean follow-up period was $66.3 \pm 44.1$ months: $60(16.6 \%)$ patients died during that period.

193 Total mortality was significantly higher among patients with ST depression than among those 194 with T wave inversion and no significant ST-T change $(P=0.001)$ (Table 1).

195 Compared to the patients who survived, those who had died were significantly older ( $71.4 \pm 9.4$ 196 vs. $64.4 \pm 12.4$ years, $\mathrm{p}<0.001$ ), and more likely to have DM, prior percutaneous transluminal 197 coronary angioplasty (PTCA), advanced CKD, advanced Killip score and lower LVEF (all 
$198 \mathrm{p}<.05)$. Those patients who died were also more likely to have an ECG pattern of ST depression than the 199 patients who survived (35.0 vs. 15.2\%, p<0.001) (Table 2). All variables with a $P$ value $\leq 0.1$ by 200 univariate analysis were put into multiple stepwise Cox regression analysis, which showed that 201 advanced Killip score (hazard ratio $[\mathrm{HR}]=3.417,95 \%$ confidence interval $(\mathrm{CI}): 1.966-5.939, P$ $202<0.001)$, age $(\mathrm{HR}=1.043,95 \% \mathrm{CI}: 1.015-1.072, P=0.002)$, prior PTCA $(\mathrm{HR}=1.987,95 \%$ CI: $2031.110-3.558, P=0.021)$, advanced CKD (HR $=1.871,95 \% \mathrm{CI}: 1.044-3.354, P=0.035)$ and 204 ECG pattern of ST depression $(\mathrm{HR}=1.809,95 \% \mathrm{CI}: 1.015-3.223, P=0.044)$ were the only 205 independent predictors of long-term mortality (Table 3).

206 Figure 1A compares the Kaplan-Meier curves for primary endpoint among patients with and 207 patients without an ECG pattern of ST depression. Long-term mortality was significantly higher 208 in patients with ST depression than in those without ST depression (Log-rank p value $<0.001$ ).

209 Figure 1B compares the Kaplan-Meier curves for primary endpoint among patients with different 210 ECG patterns. Patients with ST depression were found to have a higher rate of long-term 211 mortality than patients with $\mathrm{T}$ wave inversion and no significant ST-T changes (Log-rank p value $212<0.001)$.

\section{Secondary endpoint analysis: long-term cardiac death and non-fatal MACE}

214 Long-term cardiac death was significantly higher in patients with an ST depression ECG 215 pattern than in patients with T wave inversion and no significant ST change pattern $(P=0.001)$

216 (Table 1). There was no difference in long-term non-fatal MACE among patients with different 217 ECG patterns. The cardiac death rate was significantly higher in patients with an ST depression 218 ECG pattern than in those without ST depression (Figure 2A; Log-rank p value =0.001). In 219 Figure 2B, a comparison of Kaplan-Meier curves for cardiac death among patients with different 220 ECG patterns revealed that patients with ST depression had a higher rate of long-term cardiac 221 death than patients with T wave inversion and no significant ST-T changes (Log-rank p value $<$ 222 0.001). Kaplan-Meier curves for non-fatal MACE among patients with and without an ST 223 depression ECG patterns revealed that there was no difference in both groups (Log-rank P value $224=0.228$ ) (Figure 3A). There was no difference in non-fatal MACE among patients with ST 225 depression, no significant ST-T changes and T wave inversion (Log-rank P value $=0.482$ ) 226 (Figure 3B).

\section{Discussion}

228 There are several important findings in this study. First, NSTEMI patients presenting with an ST 
229 depression ECG pattern had a higher percentage of DM, advanced CKD and LM disease than those 230 patients presenting with other ECG patterns. Second, the NSTEMI patients presenting with an ST 231 depression ECG pattern had not only higher rates of in-hospital total mortality, cardiac death and 232 pulmonary edema but also higher rates of total mortality and cardiac death during long-term 233 follow-up. Third, an advanced Killip score, older age, advanced CKD, prior PTCA and an ST 234 235 depression ECG pattern were independent predictors of long-term total mortality.

An ST depression ECG pattern is one of the components of the TIMI risk score commonly used to predict 14-day outcomes of unstable angina and NSTEMI in clinical practice [9]. It is surprising that only a few studies have compared intermediate or long-term (using only 6-60 months of mean follow-up time) outcomes of acute coronary syndrome (ACS)/NSTEMI between patients with and without ST depression in the mainly pre-thrombolytic and thrombolytic era [10-13]. To the best of our knowledge, this is the only study to compare the long-term outcome of NSTEMI patients with and without ST depression in the intervention era. The TIMI III Registry showed that in patients with non-ST elevation ACS, an ST deviation of as little as 0.05 $\mathrm{mV}$ increased the risk of death or MI by approximately 2-fold, both at 30 days and at 1 year [10]. Hyde et al reported that ST depression of $0.05 \mathrm{mV}$ or more on the admission ECG was related to 4-year mortality rates; the risk of death increased as ST depression increased [11]. In contrast, Twave inversion of $0.1 \mathrm{mV}$ or more was associated with only a modest increase or no increase at all in the subsequent risk of death or MI in the same study [11]. In that study, $67 \%$ of patients

248 received intravenous heparin, 37\% underwent angiography, and 35\% underwent revascularization. Researchers with the GRACE study (Global Registry of Acute Coronary Events) developed a score that allows us to predict patient mortality 6 months after being discharged following an ACS episode; an ST decrease $\geq 1 \mathrm{~mm}$ was one of 9 prognostic variables used to determine the patient's probability of death [12]. It is worth noting that $33 \%$ of patients received PCI or CABG in this study, and having no in-hospital PCI was another predictor of 6month mortality. The PREDICT score is the only score developed to predict a relatively longterm prognosis (6 years) after hospitalization for ACS in the mainly pre-thrombolytic and thrombolytic era [13]. Only $11 \%$ of patients received thrombolytic therapy in the study. ST segment depression $>1 \mathrm{~mm}$ horizontal or downward sloping was a major predictor of long-term mortality in this score. Our study was conducted in the PCI era and all patients received angiography; $87 \%$ of these patients received PCI due to significant CAD. ST depression is still 
260

261

262

263

264

265

266

267

268

269

270

271

272

273

274

275

276

277

278

279

280

281

282

283

284

285

286

287

288

289

290

291

an independent predictor of in-hospital and long-term mortality. Our study confirms the previous finding that only those patients with an ST depression pattern, but not with $\mathrm{T}$ wave inversion, had a worse in-hospital and long-term mortality (more than 5 years) outcome than patients with no significant ST-T changes. An ST depression ECG pattern may be a very easy and important hint for clinical physicians to use to identify those NSTEMI patients who are at higher risk of in-hospital and long-term mortality. Patients with ST depression may need more aggressive therapy and management, including risk modification and even immediate or early intervention (for those patients with refractory angina, unstable hemodynamic status, heart failure symptoms, malignant tachyarrhythmia, or a higher TIMI or GRACE risk score, according to clinical guidelines). Further studies focusing on the role of an ST depression ECG pattern in risk stratification and the impact of immediate or early intervention on outcomes are needed for further evaluation.

A previous study showed a T-wave inversion is sensitive for ischemia but is less specific, unless it is marked $(\geq 0.3 \mathrm{mV})$ [11]. This may explain why T-wave inversion could not independently predict total mortality in previous studies and in our study.

Furthermore, our study showed that the percentages of DM, advanced CKD and LM disease were higher in patients with ST depression than in patients with other ECG patterns. A consistent finding was that the risk of adverse outcomes increased with diabetes, impaired renal function and prior CAD during ACS [5,13-18]. Among patients with CAD, LM disease was not only a strong predictor of in-hospital mortality for PCI, but was also associated with high mortality, even after successful PCI for ACS [19,20]. These findings may explain why patients with an ST depression ECG pattern in our study had worse in-hospital and long-term clinical outcomes. Our study also confirms previous findings that advanced Killip score, old age, prior PTCA and advanced CKD are strong predictors of a long-term adverse outcome [18,21-23].

\section{Study limitations}

Some limitations in this study should be noted. First, this was a retrospective cohort study. Second, this study did not include in the analysis NSTEMI patients who received conservative therapy. Therefore, this study might have selection bias. However, the clinical outcome was better in those patients who received in-hospital PCI compared with those patients who received conservative therapy, as reported in previous studies [15,24,25]. All of our patients with significant CAD received PCI during hospitalization, and ST depression was still a strong predictor of long-term mortality and cardiac death.

\section{Conclusions}


292 Our study findings suggest that among NSTEMI patients undergoing PCI, those presenting with 293 an ST depression ECG pattern had a higher percentage of DM, advanced CKD and LM disease 294 than patients without ST depression. Long-term outcomes, especially in terms of total mortality 295 and cardiac death, were worse in patients with an ST depression ECG pattern than in patients 296 without ST depression; this may be due to associated comorbidities.

\section{Acknowledgements}

298 None

299

300

301

302

303

304

305

306

307

308

309

310

311

312

313

314

315

316

317

318

319

320

321

322

323

324

325 
327

328

329

330

331

332

333

334

335

336

337

338

339

340

341

342

343

344

345

346

347

348

349

350

351

352

353

354

355

356

\section{References}

1. Nieto FJ, Bassand JP, Hamm CW, Ardissino D, Boersma E, Budaj A,Fernández-Avilés F, Fox KA, Hasdai D, Ohman EM, WallentinL, Wijns W: Guidelines for the diagnosis and treatmentof non-ST-segment elevation acute coronary syndromes. Eur Heart J. 2007; 28: 1598-1660.

2. Cannon CP, Weintraub WS, Demopoulos LA, Vicari R, Frey MJ, Lakkis N,Neumann FJ, Robertson DH, DeLucca PT, DiBattiste PM, Gibson CM,Braunwald E: Comparison of early invasive and conservative strategies in patients with unstable coronary syndromes treated with the glycoprotein IIb/IIIa inhibitor tirofiban. N Engl J Med. 2001; 344: 1879-1887.

3. Fox KA, Poole-Wilson P, Clayton TC, Henderson RA, Shaw TR, Wheatley DJ, Knight R, Pocock SJ: 5-year outcome of an interventional strategy in non-ST-elevationacute coronary syndrome: the British Heart Foundation RITA3 randomised trial. Lancet. 2005; 366: 914920.

4. Wallentin L, Swahn E, Kontny F, Husted S, Lagerqvist B, Stahle E, Nielsen JD,Dellborg M, Geiran O, Grande P, Hulting J, Kyst-Madsen J, Nordrehaug JE,Naslund U, Pilegaard H, Rollag A, Nielsen TT, Saetre H, Siegbahn A, Ohlin H, Arbeus M, Bylund H, Ekstrom L, Eriksson P, Holmgren A, Kellerth T,Lindblom D, Lindvall B, Nordrehaug J, Radegran K, Sjogren I, Stenport G,Stahl E, Svane B, Svedjeholm R, Toftegaard-Nielsen T, Hassan SY, Persson S,Jacobsson KA, Thygesen K, von der Lippe G, Julian D, Bertrand M, Wedel H,Andren B, Diderholm E, Frostfeldt G, Jernberg T, Abrahamsson P, Lindahl B, Venge P, Janzon M, Logander E, Svensson E, Lindstrom G, Alsjo G, Gulin M,Setterberg G, Wikstrom L, M-Andersen I, Seim T: Invasive compared with noninvasive treatment in unstable coronary-artery disease: FRISC II prospective randomised multicentre study. Lancet. 1999; 354: 708-715.

5. Wang HT, Chen YL, Wu CJ: Impact of chronic kidney disease on clinical outcomes in patients with non-ST elevation myocardial infarction receiving percutaneous coronary intervention - A five-year observational study. Int J Cardiol. 2016; 220:166-172.

6. Amsterdam EA, Wenger NK, Brindis RG, Casey DE Jr, Ganiats TG, Holmes DR Jr, Jaffe AS, Jneid H, Kelly RF, Kontos MC, Levine GN, Liebson PR, Mukherjee D, Peterson ED, Sabatine MS, Smalling RW, Zieman SJ; ACC/AHA Task Force Members; Society for 
357

358

359

360

361

362

363

364

365

366

367

368

369

370

371

372

373

374

375

376

377

378

379

380

381

382

383

384

385

386

387

Cardiovascular Angiography and Interventions and the Society of Thoracic Surgeons: 2014 AHA/ACC guideline for the management of patients with non-ST-elevation acute coronary syndromes: executive summary: a report of the American College of Cardiology/American Heart Association Task Force on Practice Guidelines. Circulation. 2014; 130: 2354-2394.

7. Chen YL, Chen MC, Wu CJ, Yip HK, Fang CY, Hsieh YK, Chen CJ, Yang CH, Chang HW: Impact of 6-month angiographic restenosis inside bare-metal stents on long-term clinical outcome in patients with coronary artery disease. Int Heart J. 2007; 48: 443-454.

8. Chen YL, Hang CL, Fang HY, Tsai TH, Sun CK, Chen CJ, Chen SM, Yang CH, Hsieh YK, Wu CJ, Fu M, Yip HK: Comparison of prognostic outcome between left circumflex arteryrelated and right coronary artery-related acute inferior wall myocardial infarction undergoing primary percutaneous coronary intervention. Clin Cardiol. 2011; 34: 249-253.

9. Antman EM, Cohen M, Bernink PJ, McCabe CH, Horacek T, Papuchis G, Mautner B, Corbalan R, Radley D, Braunwald E: The TIMI risk score for unstable angina/non-ST elevation MI: A method for prognostication and therapeutic decision making. JAMA. 2000; 284:835-842.

10. Cannon CP, McCabe CH, Stone PH, Rogers WJ, Schactman M, Thompson BW, Pearce DJ, Diver DJ, Kells C, Feldman T, Williams M, Gibson RS, Kronenberg MW, Ganz LI, Anderson HV, Braunwald E: The electrocardiogram predicts one-year outcome of patients with unstable angina and non-Q wave myocardial infarction: results of the TIMI III Registry ECG Ancillary Study. Thrombolysis in Myocardial Ischemia. J Am Coll Cardiol. 1997; 30:133-140.

11. Hyde TA, French JK, Wong CK, Straznicky IT, Whitlock RM, White HD: Fouryear survival of patients with acute coronary syndromes without STsegment elevation and prognostic significance of 0.5 -mm ST-segment depression. Am J Cardiol. 1999; 84:379-385.

12. Eagle KA, Lim MJ, Dabbous OH, Pieper KS, Goldberg RJ, Van de Werf F, Goodman SG, Granger CB, Steg PG, Gore JM, Budaj A, Avezum A, Flather MD, Fox KA; GRACE Investigators: A validated prediction model for all forms of acute coronary syndrome: estimating the risk of 6-month post-discharge death in an international registry. JAMA. 2004; 291:2727-2733.

13. Jacobs DR Jr, Kroenke C, Crow R, Deshpande M, Gu DF, Gatewood L, Blackburn H. 
388

389

390

391

392

393

394

395

396

397

398

399

400

401

402

403

404

405

406

407

408

409

410

411

412

413

414

415

416

417

418

PREDICT: A simple risk score for clinical severity and long-term prognosis after hospitalization for acute myocardial infarction or unstable angina: the Minnesota heart survey. Circulation. 1999; 100:599-607.

14. Cohen M: Long-term outcomes in high-risk patients with non-ST-segment elevation myocardial infarction. J Thromb Thrombolysis. 2016; 41:464-474.

15. Fox KA, Dabbous OH, Goldberg RJ, Pieper KS, Eagle KA, Van de Werf F, Avezum A, Goodman SG, Flather MD, Anderson FA Jr, Granger CB. Prediction of risk of death and myocardial infarction in the six months after presentation with acute coronary syndrome: prospective multinational observational study (GRACE). BMJ. 2006; 333:1091.

16. Roe MT, Chen AY, Thomas L, Wang TY, Alexander KP, Hammill BG, Gibler WB, Ohman EM, Peterson ED: Predicting long-term mortality in older patients after non-ST-segment elevation myocardial infarction: the CRUSADE long-term mortality model and risk score. Am Heart J. 2011; 162:875-883.e1.

17. Fox KA, Fitzgerald G, Puymirat E, Huang W, Carruthers K, Simon T, Coste P, Monsegu J, Gabriel Steg P, Danchin N, Anderson F: Should patients with acute coronary disease be stratified for management according to their risk? Derivation, external validation and outcomes using the updated GRACE risk score. BMJ Open. 2014; 4:e004425.

18. Mueller C, Neumann FJ, Perruchoud AP, Buettner HJ: Renal function and long term mortality after unstable angina/non-ST segment elevation myocardial infarction treated very early and predominantly with percutaneous coronary intervention. Heart. 2004; 90: 902-907.

19. Wu C, Hannan EL, Walford G, Ambrose JA, Holmes DR Jr, King SB 3rd, Clark LT, Katz S, Sharma S, Jones RH: A risk score to predict in-hospital mortality for percutaneous coronary interventions. J Am Coll Cardiol. 2006; 47:654-60.

20. Puricel S, Adorjan P, Oberhänsli M, Stauffer JC, Moschovitis A, Vogel R, Goy JJ, Müller O, Eeckhout E, Togni M, Wenaweser P, Meier B, Windecker S, Cook S: Clinical outcomes after PCI for acute coronary syndrome in unprotected left main coronary artery disease: insights from the Swiss Acute Left Main Coronary Vessel Percutaneous Management (SALVage) study. EuroIntervention. 2011; 7:697-704.

21. Charytan DM, Wallentin L, Lagerqvist B, Spacek R, De Winter RJ, Stern NM, Braunwald E, Cannon CP, Choudhry NK: Early angiography in patients with chronic kidney disease: a collaborative systematic review. Clin J Am Soc Nephrol. 2009; 4: 1032-1043. 
419 22. Song YB, Hahn JY, Kim JH, Lee SY, Choi SH, Choi JH, Choi SH, Lee SH, Yoon J, Kim YJ, 420 Jeong MH, Gwon HC; Korea Acute Myocardial Infarction Registry Investigators:

421 Comparison of angiographic and other findings and mortality in non-ST-segment elevation 422 versus ST-segment elevation myocardial infarction in patients undergoing early invasive 423 intervention. Am J Cardiol. 2010; 106: 1397-1403.

424 23. Rapsomaniki E, Shah A, Perel P, Denaxas S, George J, Nicholas O, Udumyan R, 425 Feder GS, Hingorani AD, Timmis A, Smeeth L, Hemingway H: Prognostic models for 426 stable coronary artery disease based on electronic health record cohort of 102023 427 patients. Eur Heart J. 2014; 35:844-852.

428 24. Wong JA, Goodman SG, Yan RT, Wald R, Bagnall AJ, WelshRC, Wong GC, Kornder J, 429 Eagle KA, Steg PG, Yan AT: Temporal management patterns and outcomes of non-ST 430 elevation acute coronary syndromes in patients with kidney dysfunction. Eur Heart J. 2009; 431 30: 549-557.

432 25. Singh M: Primary angioplasty should be performed in hospitals without on-site surgery. 433 Catheter Cardiovasc Interv. 2005; 65: 1-7. 


\section{Table 1 (on next page)}

Baseline Characteristics, Angiographic Findings and Clinical Outcomes of 362 Study Patients According to the Presenting ECG 
1 Table 1. Baseline Characteristics, Angiographic Findings and Clinical Outcomes of 362 Study

2 Patients According to the Presenting ECG

\begin{tabular}{|c|c|c|c|c|}
\hline Variables & $\begin{array}{l}\text { No ST changes } \\
\quad(n=204)\end{array}$ & $\begin{array}{l}\text { Inverted T wave } \\
\qquad(\mathrm{n}=91)\end{array}$ & $\begin{array}{l}\text { ST depression } \\
\qquad(\mathrm{n}=67)\end{array}$ & $\begin{array}{c}P \\
\text { Value }\end{array}$ \\
\hline Age (yrs) & $64.7 \pm 12.2$ & $65.2 \pm 13.4$ & $68.8 \pm 10.3$ & 0.059 \\
\hline Male gender & $77.5 \%(158)$ & $68.1 \%(62)$ & $65.7 \%(44)$ & 0.084 \\
\hline Current smoker & $24.0 \%(49)$ & $28.6 \%(26)$ & $17.9 \%(12)$ & 0.301 \\
\hline Hypertension & $74.5 \%(152)$ & $70.3 \%(64)$ & $76.1 \%(51)$ & 0.669 \\
\hline Diabetes mellitus & $46.1 \%(94)^{\mathrm{a}}$ & $35.2 \%(32)^{\mathrm{a}}$ & $52.2 \%(35)^{b}$ & 0.080 \\
\hline Dyslipidemia & $38.7 \%(79)$ & $36.3 \%(33)$ & $37.3 \%(25)$ & 0.918 \\
\hline Old stroke & $16.2 \%(33)$ & $22.0 \%(20)$ & $19.4 \%(13)$ & 0.473 \\
\hline Old MI & $8.8 \%(18)^{\mathrm{a}}$ & $17.6 \%(16)^{\mathrm{b}}$ & $17.9 \%(12)^{\mathrm{b}}$ & 0.042 \\
\hline Advanced CKD* & $40.2 \%(82)^{\mathrm{a}}$ & $44.0 \%(40)^{\mathrm{a}}$ & $65.7 \%(44)^{b}$ & $<0.001$ \\
\hline PVD & $3.4 \%(7)$ & $4.4 \%(4)$ & $7.5 \%(5)$ & 0.379 \\
\hline Prior PTCA & $15.2 \%(31)$ & $13.2 \%(12)$ & $23.9 \%(16)$ & 0.161 \\
\hline Prior CABG & $0 \%(0)^{\mathrm{a}}$ & $3.3 \%(3)^{b}$ & $6.0 \%(4)^{b}$ & 0.005 \\
\hline BMI (kg/m2) & $25.4 \pm 3.6^{\mathrm{a}}$ & $24.1 \pm 3.4^{b}$ & $25.2 \pm 3.6^{\mathrm{ab}}$ & 0.020 \\
\hline Advanced Killip & $12.7 \%(26)^{\mathrm{a}}$ & $19.8 \%(18)^{\mathrm{ab}}$ & $32.8 \%(22)^{b}$ & 0.001 \\
\hline score $^{\dagger}$ & & & & \\
\hline LVEF $(\%)$ & $60.7 \pm 12.3$ & $59.3 \pm 14.6$ & $56.2 \pm 15.3$ & 0.070 \\
\hline $\begin{array}{l}\text { Creatinine level } \\
(\mathrm{mg} / \mathrm{dl})\end{array}$ & $1.33 \pm 1.07^{\mathrm{a}}$ & $1.26 \pm 0.85^{\mathrm{a}}$ & $1.87 \pm 1.70^{\mathrm{b}}$ & 0.002 \\
\hline eGFR & $68.1 \pm 28.7^{\mathrm{a}}$ & $66.6 \pm 28.5^{\mathrm{a}}$ & $51.2 \pm 25.3^{b}$ & $<0.001$ \\
\hline
\end{tabular}




\begin{tabular}{|c|c|c|c|c|}
\hline Troponin-I (ng/ml) & $9.88 \pm 24.6^{\mathrm{ab}}$ & $7.4 \pm 9.8^{b}$ & $19.4 \pm 50.0^{\mathrm{a}}$ & 0.025 \\
\hline \multicolumn{5}{|l|}{ CAG/PTCA finding } \\
\hline Time to & & & & 0.654 \\
\hline \multicolumn{5}{|l|}{ angiography } \\
\hline$<24$ hours & $38.7 \%(79)$ & $45.1 \%(41)$ & $37.3 \%(25)$ & \\
\hline 24-48 hours & $12.7 \%(26)$ & $12.1 \%(11)$ & $17.9 \%(12)$ & \\
\hline 48-72 hours & $48.5 \%(99)$ & $42.9 \%(39)$ & $44.8 \%(30)$ & \\
\hline Significant CAD & $89.2 \%(182)$ & $84.6 \%(77)$ & $82.1 \%(55)$ & 0.259 \\
\hline Multiple-vessel & $67.2 \%(137)$ & $62.6 \%(57)$ & $71.6 \%(48)$ & 0.489 \\
\hline \multicolumn{5}{|l|}{ disease } \\
\hline LM & $9.8 \%(20)^{\mathrm{a}}$ & $12.1 \%(11)^{\mathrm{a}}$ & $25.4 \%(17)^{b}$ & 0.005 \\
\hline Total stent number & $1.6 \pm 1.1$ & $1.5 \pm 1.1$ & $1.8 \pm 1.4$ & 0.255 \\
\hline Stent type & & & & 0.277 \\
\hline Drug eluting stent & $45.6 \%(93)$ & $48.4 \%(44)$ & $34.3 \%(23)$ & \\
\hline Bare metal stent & $43.6 \%(89)$ & $37.4 \%(34)$ & $47.8 \%(32)$ & \\
\hline Final TIMI-3 flow & $98.0 \%(200)$ & $98.9 \%(90)$ & $100.0 \%(67)$ & 0.474 \\
\hline Complete & $93.1 \%(190)$ & $93.4 \%(85)$ & $89.6 \%(60)$ & 0.585 \\
\hline \multicolumn{5}{|l|}{ revascularization } \\
\hline \multicolumn{5}{|l|}{ Medication } \\
\hline Aspirin & $81.9 \%(167)^{\mathrm{a}}$ & $79.1 \%(72)^{\mathrm{a}}$ & $70.1 \%(47)^{b}$ & 0.124 \\
\hline Clopidogrel & $89.7 \%(183)^{\mathrm{a}}$ & $81.3 \%(74)^{\mathrm{b}}$ & $85.1 \%(57)^{\mathrm{ab}}$ & 0.132 \\
\hline $\mathrm{ACEI} / \mathrm{ARB}$ & $70.1 \%(143)$ & $64.8 \%(59)$ & $61.2 \%(41)$ & 0.350 \\
\hline Beta-blocker & $63.7 \%(130)$ & $68.1 \%(62)$ & $56.7 \%(38)$ & 0.337 \\
\hline Statin & $56.9 \%(116)$ & $54.9 \%(50)$ & $56.7 \%(38)$ & 0.952 \\
\hline
\end{tabular}




\begin{tabular}{|c|c|c|c|c|}
\hline \multicolumn{5}{|l|}{ In-hospital events } \\
\hline Total mortality & $2.9 \%(6)^{\mathrm{a}}$ & $1.1 \%(1)^{\mathrm{a}}$ & $9.0 \%(6)^{b}$ & 0.024 \\
\hline Cardiac death & $2.5(5)^{\mathrm{a}}$ & $0 \%(0)^{\mathrm{a}}$ & $7.5 \%(5)^{b}$ & 0.017 \\
\hline VT/VF & $2.9 \%(6)$ & $2.2 \%(2)$ & $4.5 \%(3)$ & 0.706 \\
\hline $\mathrm{PE}$ & $17.2 \%(35)^{\mathrm{a}}$ & $18.7 \%(17)^{\mathrm{a}}$ & $46.3 \%(31)^{b}$ & $<0.001$ \\
\hline \multicolumn{5}{|l|}{ Long-term outcome } \\
\hline $\begin{array}{l}\text { Follow-up duration } \\
\text { (months) }\end{array}$ & $69.7 \pm 43.9^{a}$ & $72.1 \pm 43.8^{a}$ & $48.0 \pm 41.2^{\mathrm{b}}$ & 0.001 \\
\hline Total mortality & $15.2 \%(31)^{\mathrm{a}}$ & $8.8 \%(8)^{\mathrm{a}}$ & $31.3 \%(21)^{\mathrm{b}}$ & 0.001 \\
\hline Cardiac death & $7.4 \%(15)^{\mathrm{a}}$ & $0.0 \%(0)^{\mathrm{b}}$ & $14.9 \%(10)^{\mathrm{c}}$ & 0.001 \\
\hline MACE $\ddagger$ & $31.9 \%(65)$ & $35.2 \%(32)$ & $32.8 \%(22)$ & 0.856 \\
\hline TVR & $14.2 \%(29)$ & $12.1 \%(11)$ & $13.4 \%(9)$ & 0.885 \\
\hline MI & $9.3 \%(19)$ & $13.2 \%(12)$ & $9.0 \%(6)$ & 0.556 \\
\hline Stroke & $4.9 \%(10)$ & $5.5 \%(5)$ & $4.5 \%(3)$ & 0.956 \\
\hline Heart failure & $9.8 \%(20)$ & $9.9 \%(9)$ & $13.4 \%(9)$ & 0.686 \\
\hline
\end{tabular}

3 Data are expressed as means $\pm \mathrm{SD}$ or $\%(n)$.

$4 \mathrm{ACEI} / \mathrm{ARB}=$ angiotensin-converting enzyme inhibitors/angiotensin-receptor blockers, $\mathrm{BMI}=$

5 body mass index, $\mathrm{CABG}=$ coronary artery bypass surgery, $\mathrm{CAG}=$ coronary angiography, $\mathrm{ECG}$

$6=$ electrocardiogram, eGFR $=$ estimated glomerular filtration rate, $\mathrm{ESRD}=$ end stage renal

7 disease, $\mathrm{HF}=$ heart failure, $\mathrm{LVEF}=$ left ventricular ejection fraction, $\mathrm{MACE}=$ major adverse

8 cardiac event, $\mathrm{MI}=$ myocardial infarction, $\mathrm{PCI}=$ percutaneous cardiac intervention, $\mathrm{PE}=$

9 pulmonary edema, $\mathrm{PTCA}=$ percutaneous transluminal coronary angioplasty, $\mathrm{PVD}=$ peripheral

10 vascular disease, $\mathrm{TIMI}=$ thrombolysis in myocardial infarction, $\mathrm{TVR}=$ target vessel

11 revascularization, $\mathrm{VF}=$ ventricular fibrillation, $\mathrm{VT}=$ ventricular tachycardia. 
$12 * \mathrm{eGFR}<60 \mathrm{ml} / \mathrm{min} / 1.73 \mathrm{~m}^{2}$

$13 \dagger$ Killip score $\geq 3$.

$14 \$$ Target vessel revascularization, myocardial infarction, stroke and hospitalization for heart 15 failure.

16 Different letters (a, b, c, i.e., ${ }^{a}$ vs. ${ }^{b}$, vs. $\left.{ }^{c}\right)$ indicate significant difference between groups $17(\mathrm{P}<0.05)$. 
Table 2 (on next page)

Baseline Characteristics, Angiographic Findings and Clinical Outcomes of 362 Study Patients With and Without Long Term Mortality 
1 Table 2. Baseline Characteristics, Angiographic Findings and Clinical Outcomes of 362 Study

2 Patients With and Without Long Term Mortality

\begin{tabular}{|c|c|c|c|}
\hline Variables & $\begin{array}{c}\text { Mortality } \\
(\mathrm{n}=60)\end{array}$ & $\begin{array}{c}\text { Alive } \\
(\mathrm{n}=302)\end{array}$ & $P$ Value \\
\hline Age (yrs) & $71.4 \pm 9.4$ & $64.4 \pm 12.4$ & $<0.001$ \\
\hline Male gender & $65.0 \%(39)$ & $74.5 \%(225)$ & 0.130 \\
\hline Current smoker & $16.7 \%(10)$ & $25.5 \%(77)$ & 0.185 \\
\hline Hypertension & $78.3 \%(47)$ & $72.8 \%(220)$ & 0.425 \\
\hline Diabetes mellitus & $60.0 \%(36)$ & $41.4 \%(125)$ & 0.010 \\
\hline Dyslipidemia & $38.3 \%(23)$ & $37.7 \%(114)$ & 0.932 \\
\hline Old stroke & $23.3 \%(14)$ & $17.2 \%(52)$ & 0.263 \\
\hline Old myocardial infarction & $13.3 \%(8)$ & $12.6 \%(38)$ & 0.873 \\
\hline Prior PTCA & $28.3 \%(17)$ & $13.9 \%(42)$ & 0.006 \\
\hline Prior CABG & $1.7 \%(1)$ & $2.0 \%(6)$ & 1.000 \\
\hline Peripheral vascular disease & $8.3 \%(5)$ & $3.6 \%(11)$ & 0.106 \\
\hline Advanced CKD* & $66.7 \%(40)$ & $41.7 \%(126)$ & 0.001 \\
\hline Body mass index $\left(\mathrm{kg} / \mathrm{m}^{2}\right)$ & $25.1 \pm 3.8$ & $25.0 \pm 3.5$ & 0.932 \\
\hline Advance Killip score ${ }^{\dagger}$ & $43.3 \%(26)$ & $13.2 \%(40)$ & $<0.001$ \\
\hline Troponin-I & $19.6 \pm 52.5$ & $9.3 \pm 21.2$ & 0.137 \\
\hline LVEF & $54.5 \pm 13.9$ & $60.5 \pm 13.5$ & 0.003 \\
\hline Time to angiography & & & 0.177 \\
\hline$<24$ hours & $30.0 \%(18)$ & $42.1 \%(127)$ & \\
\hline 24-48 hours & $18.3 \%(11)$ & $12.6 \%(38)$ & \\
\hline 48-72 hours & $51.7 \%(31)$ & $45.4 \%(137)$ & \\
\hline
\end{tabular}




\begin{tabular}{lccc} 
ECG changes & & & $<.001$ \\
ST depression & $35.0 \%(21)$ & $15.2 \%(46)$ & \\
No ST depression & $65.0 \%(39)$ & $84.8 \%(256)$ & \\
Multiple-vessel disease & $66.7 \%(40)$ & $66.9 \%(202)$ & 0.974 \\
Left main disease & $20.0 \%(12)$ & $11.9 \%(36)$ & 0.092 \\
Total stent number & $1.4 \pm 1.0$ & $1.3 \pm 0.7$ & 0.326 \\
Stent type & & & 0.407 \\
$\quad$ Drug eluting stent & $36.7 \%(22)$ & $45.7 \%(138)$ & \\
$\quad$ Bare metal stent & $50.0 \%(30)$ & $41.4 \%(125)$ & \\
Post-PCI TIMI-3 flow & $96.7 \%(58)$ & $99.0 \%(299)$ & 0.156 \\
Complete revascularization & $91.7 \%(55)$ & $92.7 \%(280)$ & 0.778 \\
\hline
\end{tabular}

3 Data are expressed as means $\pm \mathrm{SD}$ or $\%(\mathrm{n})$.

$4 \mathrm{CABG}=$ coronary artery bypass surgery, $\mathrm{CKD}=$ chronic kidney disease, $\mathrm{ECG}=$

5 electrocardiogram, ESRD = end stage renal disease, $\mathrm{LVEF}=$ Left Ventricular Ejection fraction,

$6 \mathrm{PCI}=$ percutaneous cardiac intervention, $\mathrm{PTCA}=$ percutaneous transluminal coronary

7 angioplasty, $\mathrm{TIMI}=$ Thrombolysis in Myocardial Infarction.

$8 *$ estimated glomerular filtration rate $<60 \mathrm{ml} / \mathrm{min} / 1.73 \mathrm{~m}^{2}$

$9 \dagger$ Killip score $\geq 3$ 


\section{Table 3 (on next page)}

Univariate and Multivariate Analysis of Predictors for Long-Term Mortality 
1 Table 3. Univariate and Multivariate Analysis of Predictors for Long-Term Mortality

\begin{tabular}{|c|c|c|c|c|}
\hline \multirow[t]{3}{*}{ Variables } & \multicolumn{2}{|c|}{ Univariate analysis } & \multicolumn{2}{|c|}{ Multivariate analysis } \\
\hline & HR & P Value & HR & $\mathrm{P}$ \\
\hline & $(95 \% \mathrm{CI})$ & & $(95 \% \mathrm{CI})$ & Value \\
\hline \multirow[t]{2}{*}{ Advanced Killip score* } & 5.436 & $<0.001$ & 3.417 & $<0.001$ \\
\hline & $(3.232-9.143)$ & & $(1.966-5.939)$ & \\
\hline \multirow[t]{2}{*}{ Age (year) } & 1.065 & $<0.001$ & 1.043 & 0.002 \\
\hline & $(1.039-1.093)$ & & $(1.015-1.072)$ & \\
\hline \multirow[t]{2}{*}{ Prior PTCA } & 2.443 & 0.002 & 1.987 & 0.021 \\
\hline & $(1.391-4.293)$ & & $(1.110-3.558)$ & \\
\hline \multirow[t]{2}{*}{ Advanced $\mathrm{CKD}^{\dagger}$} & 2.782 & $<0.001$ & 1.871 & 0.035 \\
\hline & $(1.670-4.636)$ & & $(1.044-3.354)$ & \\
\hline \multirow[t]{2}{*}{ ST depression } & 3.113 & $<0.001$ & 1.809 & 0.044 \\
\hline & $(1.826-5.308)$ & & $(1.015-3.223)$ & \\
\hline \multirow[t]{2}{*}{ LM disease } & 2.516 & 0.005 & 1.919 & 0.094 \\
\hline & $(1.326-4.775)$ & & $(1.069-3.445)$ & \\
\hline \multirow[t]{2}{*}{$\mathrm{DM}$} & 2.067 & 0.006 & 1.083 & 0.784 \\
\hline & $(1.232-3.467)$ & & $(0.611-1.922)$ & \\
\hline \multirow[t]{2}{*}{ LVEF (\%) } & 0.967 & $<0.001$ & 1.002 & 0.868 \\
\hline & $(0.950-0.985)$ & & $(0.981-1.023)$ & \\
\hline
\end{tabular}

$2 \mathrm{CI}=$ confidence interval, $\mathrm{CKD}=$ chronic kidney disease, $\mathrm{DM}=$ diabetes mellitus, $\mathrm{HR}=$ hazard

3 ratio, $\mathrm{LM}=$ left main, $\mathrm{LVEF}=$ left ventricular ejection fraction, $\mathrm{PTCA}=$ percutaneous

4 transluminal coronary angioplasty,

$5 *$ Killip score $\geq 3$. 
$6 \dagger$ estimated glomerular filtration rate $<60 \mathrm{ml} / \mathrm{min} / 1.73 \mathrm{~m}^{2}$. 7 


\section{Figure 1}

Kaplan-Meier estimates of total mortality among patients with different ST segment morphology on the presenting electrocardiography

A) Kaplan-Meier estimates of total mortality among patients with and without ST depression on the presenting electrocardiography. The analysis reveals that the overall survival rate at 66 months was significantly lower in the ST depression group than in the no-ST depression group (69.7\% versus 88.5\%, Log-rank P value $<0.001)$. B) Kaplan-Meier estimates of total mortality among patients with no significant ST-T change, ST depression and T wave inversion on presenting electrocardiography. The analysis reveals that the overall survival rate at 66 months was significantly lower in the ST depression group than in the no significant ST-T change and T wave inversion group (69.7\% versus $87.4 \%$ versus $91.0 \%$, Logrank $P$ value $<0.001$ )

A)

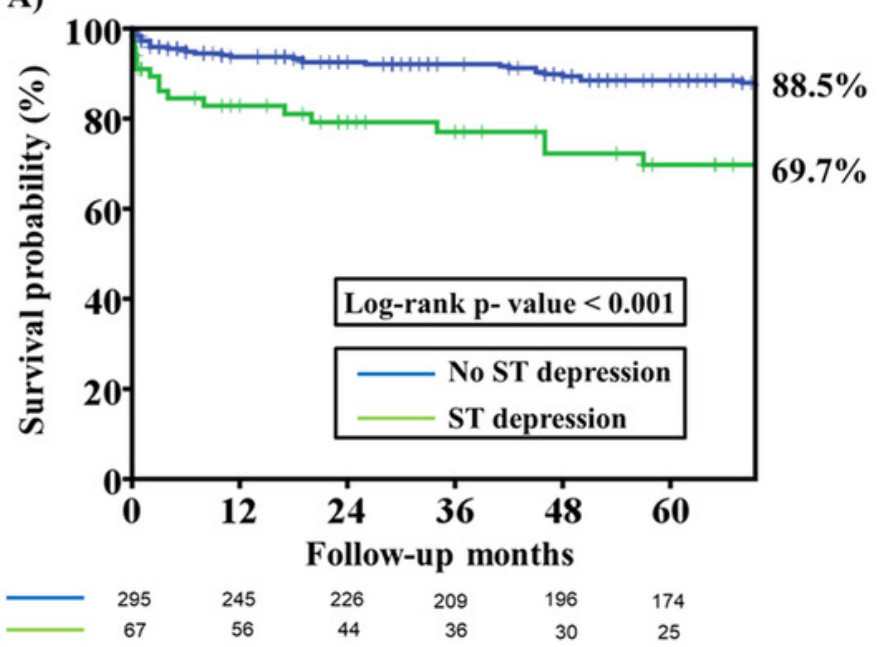

B)

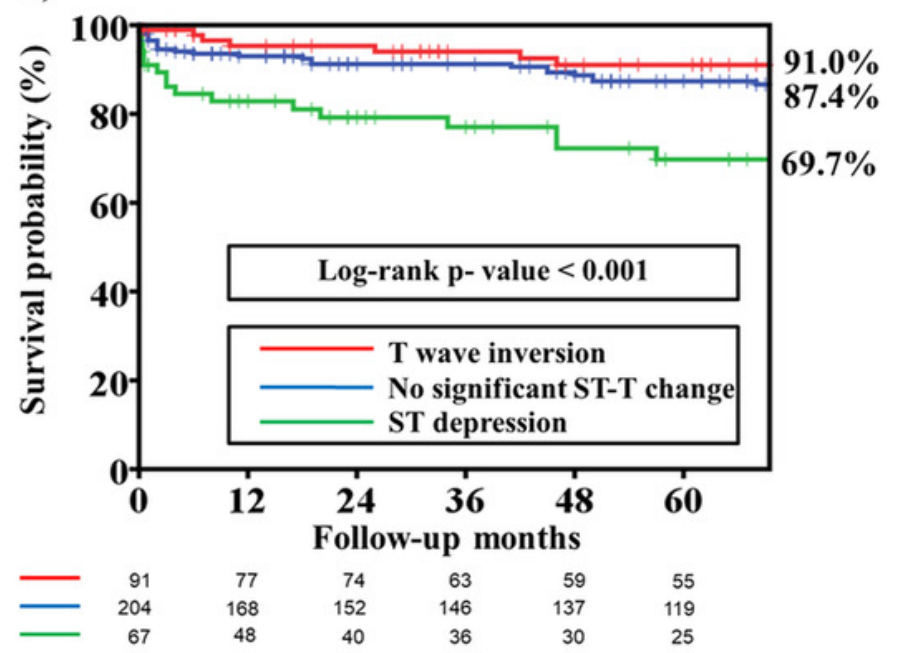




\section{Figure 2}

Kaplan-Meier estimates of cardiac death among patients with different ST segment morphology on the presenting electrocardiography

A) Kaplan-Meier estimates of cardiac death among patients with and without ST depression on the presenting electrocardiography. The analysis reveals that the freedom from cardiac death rate at 66 months was significantly lower in the ST depression group than in the no-ST depression group (87.4\% versus 95.1\%, Log-rank $\mathrm{P}$ value $=0.001)$. B) Kaplan-Meier estimates of cardiac death among patients with no significant ST-T change, ST depression and T wave inversion on the presenting electrocardiography. The analysis reveals that the freedom from cardiac death rate at 66 months was significantly lower in the ST depression group than in the no significant ST-T change and T wave inversion group $(87.4 \%$ versus 93.0\% versus $100 \%$, L og-rank $P$ value $<0.001)$.

A)

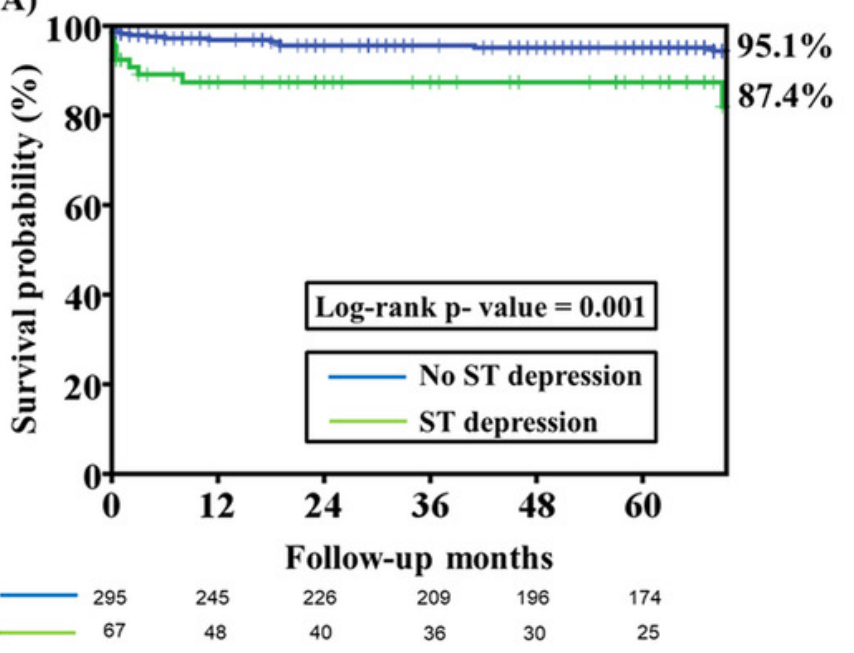

B)

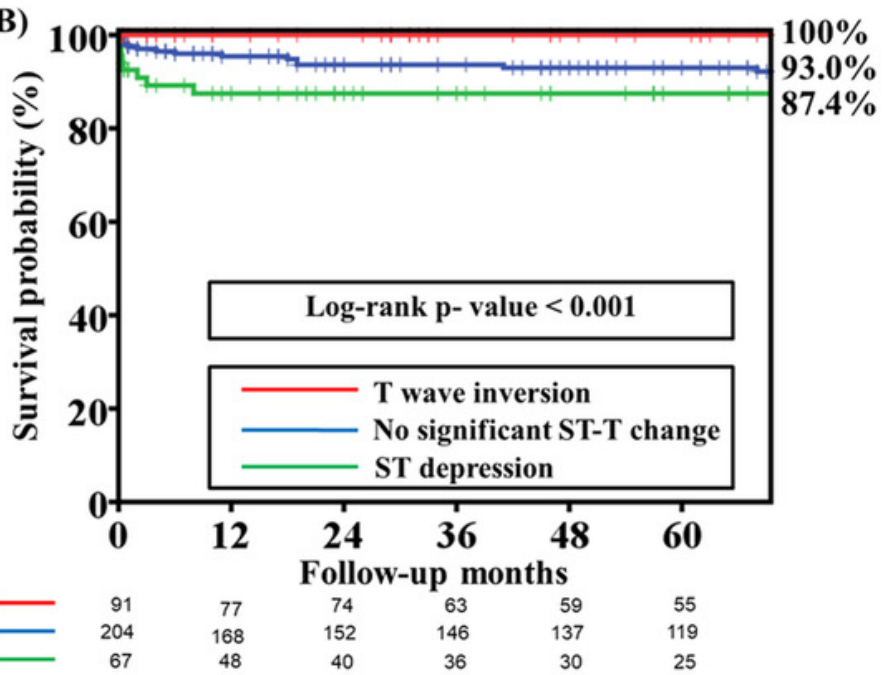




\section{Figure 3}

Kaplan-Meier estimates of non-fatal major adverse cardiac events (MACE) among patients with different ST segment morphology on the presenting electrocardiography

A) Kaplan-Meier estimates of non-fatal MACE, which were defined as target vessel

revascularization, myocardial infarction, stroke, and hospitalization for heart failure, among patients with and without ST depression on the presenting electrocardiography. The analysis illustrates that there was no difference in the freedom from non-fatal MACE rate at 66 months among patients with ST depression and no-ST depression ECG patterns $(61.7 \%$ versus $65.6 \%$, Log-rank $P$ value $=0.228$ ). B) Kaplan-Meier estimates of non-fatal MACE among patients with no significant ST-T change, ST depression and T wave inversion on the presenting electrocardiography. The analysis reveals that there were no differences in nonfatal MACE among patients with ST depression, no significant ST-T changes and T wave inversion (61.7\% versus $64.9 \%$ versus $67.2 \%$, Log-rank $P$ value $=0.482$ ).

A)

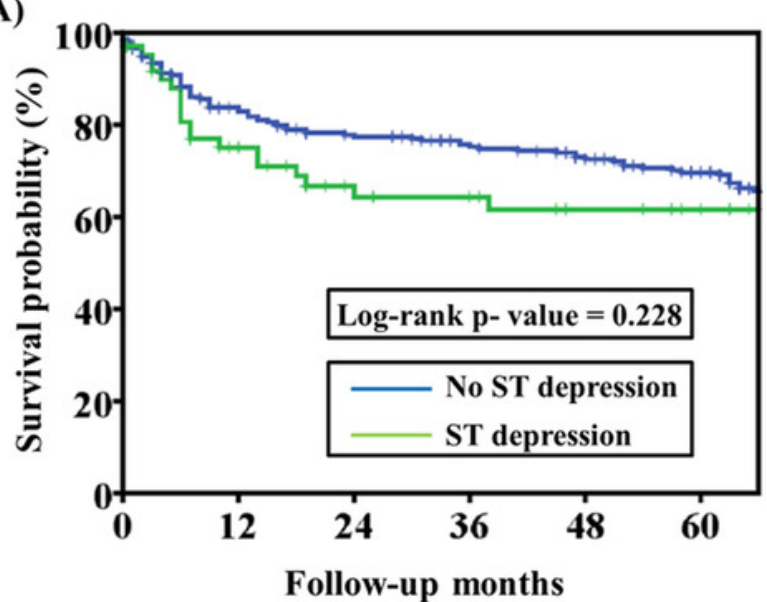

$\begin{array}{rrrrrrr}- & 295 & 213 & 190 & 174 & 158 & 135 \\ - & 67 & 38 & 28 & 26 & 20 & 16\end{array}$
$65.6 \%$ $61.7 \%$

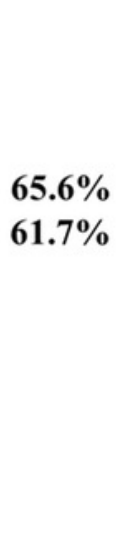

B)

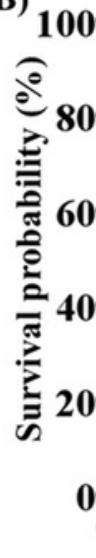

$67.2 \%$ $64.9 \%$ $61.7 \%$
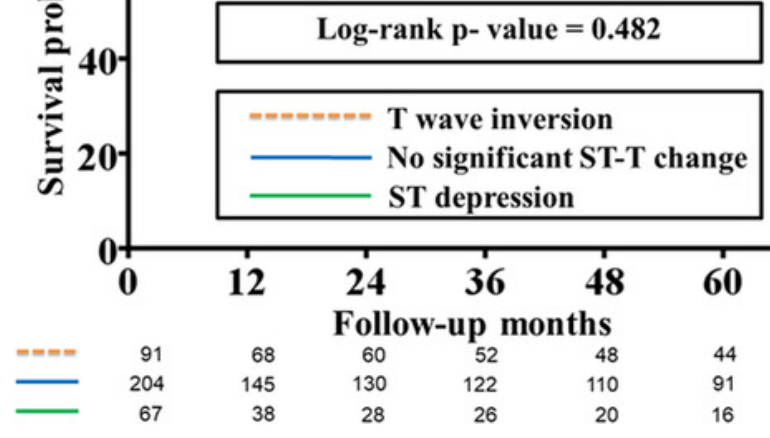

Follow-up months

\begin{tabular}{|c|c|c|c|c|}
\hline \multicolumn{5}{|c|}{ P } \\
\hline 68 & 60 & 52 & 48 & 44 \\
\hline 145 & 130 & 122 & 110 & 91 \\
\hline 38 & 28 & 26 & 20 & 16 \\
\hline
\end{tabular}

